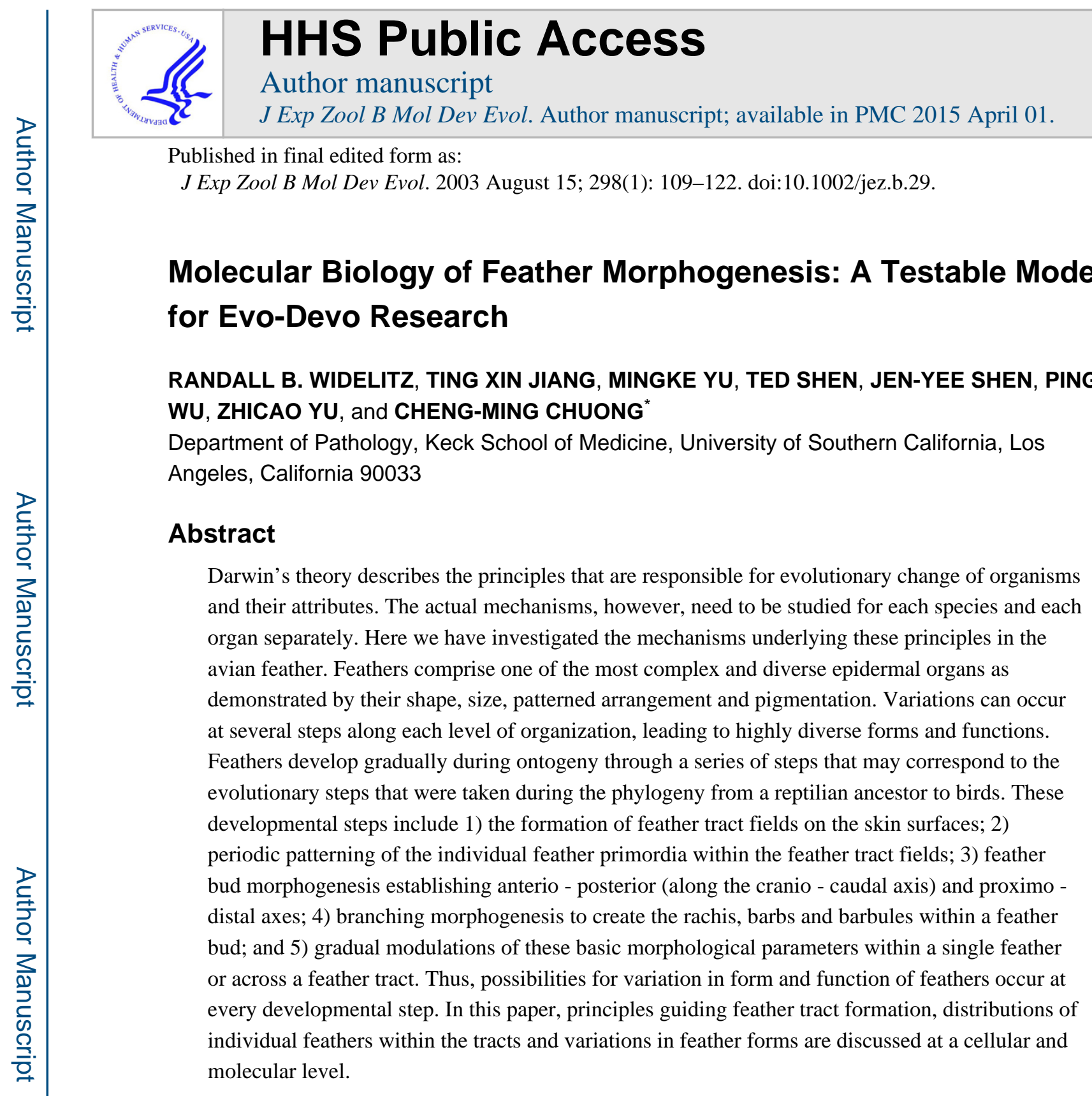

\title{
THE LIFE CYCLE OF A FEATHER
}

The integument of domestic chickens provides a wonderful opportunity to examine the molecular bases for developmental and evolutionary change. Different feathers serve diverse functions, mainly thermo-regulation, communicational display and flight. The life cycle of a feather is summarized in Fig. 1A (Chuong, '93). Each step within this cycle is initiated and regulated by processes at the molecular level, which are determined at the genetic level. Hence genetic modifications can fundamentally affect the final feather, as can be observed in the feather diversity of extant birds (see also Bartels et al., '92 and this issue).

Experimental procedures to elucidate the molecular pathways (signaling, induction, etc.) are

() 2003 Wiley-Liss, Inc.

*Correspondence to: HMR 315B, Department of Pathology, Keck School of Medicine, University of Southern California, 2011 Zonal Avenue, Los Angeles, CA 90033. chuong@ pathfinder.hsc.usc.edu. 
practical because fertilized eggs are readily available, different stages of feathers are accessible to surgical and molecular manipulations (Chen and Chuong, '99), and there is a catalog of historical knowledge pertaining to their evolution and variations (Lucas and Stettenheim, '72; Sengel, '76; Chuong et al., 2000, 2001; Prum and Brush, 2002; see Sawyer and Knapp, this issue). Feather structure is complex, yet highly organized. Since they are not essential to survival, altered feathers can form and demonstrate the effects of experimental manipulations. The complex topological transformation can be appreciated from tissue sections (Fig. 1B).

It has been shown that elaborate feather forms result from multi-level morphogenetic processes. First tracts, regions that will contain feathers, are established. Then the life cycle of the feather starts (Fig. 1A). Through a process of induction, the mesenchyme signals to the epithelium to begin to build a feather bud. A thickened epithelial placode and mesenchymal condensation forms at the site of feather bud initiation. Feather primordia grow to form symmetric and later asymmetric feather buds Latent molecular asymmetries precede the organization of the feather asymmetries. As the feather buds elongate, they invaginate into the skin and form feather follicles Feather filaments grow from the feather follicles. Branches emerge from the feather filaments as they continue to grow and differentiate (Fig. 1A).

This process is highly interactive and through a series of stimulatory and inhibitory signals, the feather primordia are arranged so each feather primordium is surrounded by a hexagonal array of other feather primordia (Jiang et al., '92). The highly ordered periodic patterns do not depend on pre-determined codes designating cells to follow specific fates. Rather, they rely upon an interplay between the physico-chemical properties of interacting cells and their environment. Hence, a homogenous cell population becomes patterned through an equilibrium of cell properties including cell adhesion/repulsion, proliferation/differentiation, signaling, migration and apoptosis. Feather patterns, like fingerprints, are formed through random interactions that are constrained by rules of organization, rather than by directing individual cells to specific locations and to specific fates.

\section{FEATHER MORPHOGENESIS STARTS FROM THE FORMATION OF FEATHER TRACT FIELDS, COMPOSED OF COMPETENT EPITHELIA AND MESENCHYMA}

Feathers are clustered in distinct feather tracts, or pterylae, which are bordered by apteria (Lucas and Stettenheim, '72). Apteria are devoid of contour feathers, but may bear other feather types. The arrangement of these tracts on the skin is called macropatterning, in contrast to micropatterning, which relates to the arrangement of individual feathers within a feather tract (Sengel, ' 78 ). The chicken has about 20 feather tracts (Lucas and Stettenheim, '72). Feathers within different tracts differ in orientation and organization (Mayerson and Fallon, '85). Since the size and shape of feathers in different tracts also vary widely from one another, tracts represent the first organization level that leads to feather diversity. 
Some of the differences observed between tracts may be attributed to the different origins of the mesenchyme. For example, the dermis from the dorsal tract is derived from the medial dermomyotome of the somites (Olivera-Martinez et al., 2002). The survival and migration of these dermal precursors require signals derived from the dorsal neural tube (OliveraMartinez et al., 2001). Classical experiments revealed the nature of the interactions between tracts. Removal of a segment of a somite including the dermatome, led to a decreased spinal tract size. Surprisingly, adjacent femoral tracts could expand into the integument territory previously occupied by the spinal tracts (Sengel, '76). This implies that the distinct tract pattern is not fixed and unchangeable, but is the result of competition among the competent mesenchymal cells from different tracts for the limited space of competent epithelia. It also shows the embryonic epithelial stem cells have the pluripotentiality to become tract or apteric regions, and be incorporated into different tracts.

The molecular mechanisms underlying the induction and the specificity of feather tracts are currently unknown. To test the role of molecules in these processes, cells secreting exogenous proteins can be implanted into embryonic tissues. One recent attempt showed that cells secreting Wnt- 1 can mimic the dorsal neural tube and induce a feathered skin (Olivera-Martinez et al., 2001). In this study a Wnt-1 producing cell line was grafted to the embryos after removal of the neural tube and notochord. The Wnt-1 rescued embryos can develop feathers with the same temporal and spatial distribution as control embryos and each feather is within the normal size range. Wnt- 1 is known to block the degradation of $\beta$ catenin, so $\beta$-catenin accumulates within the cell, moves to the nucleus and activates transcription in conjunction with Lefs/Tcfs (Brantjes et al., 2002).

\section{$\beta$-catenin confers stem cell competence within feather tracts}

Interestingly, $\beta$-catenin is one of the earliest and most distinct molecular expression patterns found to date within the feather tract (Fig. 2A). As the skin forms at approximately embryonic day 6.5 (E6.5), it differentiates into the various feather tracts. Genes involved in tract formation are likely to be expressed prior to the actual establishment of the tracts. $\beta$ catenin is one such gene that is homogeneously expressed at a moderate level within the epithelium of each feather tract as it initially forms (Jiang et al., '99; Widelitz et al., 2000). Feather primordia then gradually emerge, followed by the establishment of a circumferential zone around each primordium with inhibited feather bud formation. Since feathers within a tract are laid out bilaterally, beyond the primary row, this translates to a lateral inhibition. The next feather bud will form just outside this region. As subsequent feather buds form in the row, the space between buds, marked by decreased $\beta$-catenin expression, increases in size, while the boundaries of the forming feather buds become sharper and slightly reduced in size.

The function of $\beta$-catenin has been studied in the skin of several species. In human skin studies, $\beta$-catenin activity has been correlated with self-renewing and pluripotential epithelial stem cells, and the level of its activity can decide epidermal cell fate. Ectopic expression of an active $\beta$-catenin form in mouse epidermis induced these putative stem cells to form new hair follicles and hair follicle tumors (Gat et al., '98). Suppression of $\beta$-catenin with an inactive, truncated form of $\beta$-catenin, missing the central armadillo repeat regions, 
showed inhibited growth and diminished transcriptional activation activity as measured with TOPFLASH, a $\beta$-catenin promoter driving the expression of luciferase (Zhu and Watt, '99). With Cre-loxP mediated tissue knock out of $\beta$-catenin in the skin (using K14 Cre), hair formation was inhibited at a very early stage. It was suggested that $\beta$-catenin regulated stem cell fate, with high levels favoring the formation of hair follicles and low levels favoring the formation of inter-follicular epidermis (Huelsken et al., 2001). In chicken skin, ectopic expression of $\beta$-catenin in apteric epidermis induces new feather buds (Noramly et al., '99). When $\beta$-catenin is over expressed in scale epidermis, it converted part of the flat scales into elongated feathers (Widelitz et al., 2000). Clearly $\beta$-catenin plays an important role in the induction and fate determination of skin appendages.

\section{THE PERIODIC PATTERNED ARRANGEMENT OF FEATHER PRIMORDIA WITHIN A FEATHER TRACT FIELD RESULTS FROM THE INTERPLAY OF MOLECULES WITH POSITIVE OR NEGATIVE ROLES ON FEATHER PRIMORDIUM FORMATION}

Once the feather tract is established, individual feather primordia are laid out in specific arrangements, leading to distinct patterns. These exquisite patterns have inspired scientists to think about how such regular patterns arise (Sengel, '76). Some scientists thought it might be based on positional information and the well-coordinated x,y axis values (Wolpert, '71). Some wrote mathematical models to show that sequential formation is important and that the lateral rows are formed using the medial rows as templates (Murray et al., '83; Oster et al., '83). Some thought that gene regulating enhancer elements might turn on specific inducing molecules and thus form the feather primordia. All of these models assume feather patterning is the product of inherent positional codes across the feather field. But, how are such differences set up in the first place? To find the earliest event in patterning, a model in which all the cells have an equivalent opportunity to become either feather primordia or inter-primordial skin must be used. Here we will describe the expression pattern of signaling molecules and then introduce a reconstitution assay in which all cells are reset to a zero state with no latent molecular signals designating positional cues.

\section{Signaling molecules are identified that activate or inhibit the formation of feather primordia}

To understand the molecular basis of these processes, the molecular expression sequences during feather development were studied (Chuong et al., '96; Jung et al., '98, Noramly and Morgan, '98; Crowe et al., '98; Viallet et al., '98). By the patterns of their expression, molecules can be categorized into two modes (Fig. 3C). Some are expressed in a restrictive mode, initiating with a moderate level all over the tract, then intensifying over time within the feather primordia and diminishing outside of the feather primordia, or vice versa. Others, in a de novo mode, are expressed later and pop out directly in the primordia or the interprimordia regions. For example, Wnt-7a, follistatin and $\beta$-catenin follow the restrictive mode (Patel et al., '99; Widelitz et al., 2000). Sonic hedgehog (SHH), Delta-1, Notch-1, L-fringe, R-fringe and Eph-A4 follow the de novo mode (Ting-Berreth and Chuong, '96a; Chen et al., '97; Crowe et al., '98; Viallet et al., '98; Patel et al., '99; Chen and Chuong, 2000). 
Molecules expressed following the restrictive mode are involved in the initial induction and shaping of the feather primordia. Since molecules expressed following the de novo mode appear later, they affect events after induction.

What roles do these molecules play during feather formation? One approach is to place protein coated beads on top of skin explant cultures which are released over time forming a protein gradient (Widelitz et al., '96; Jung et al., '98). The other is to introduce molecular mis-expression to embryos in ovo using RCAS retroviral mediated gene expression for prolonged exposure to a protein (Morgan and Fekete, '96). Using these approaches, signaling molecules can be tested as to whether they function as activators that enhance the size of individual feather primordia or the number of feather primordia, and inhibitors that suppress them (Noveen et al., '95; Ting-Berreth and Chuong, '96a,b; Song et al., '96; Noramly and Morgan, '98; Crowe et al., '98; Viallet et al., '98; Patel et al., '99). Among the activators are Shh, FGF4, Noggin, follistatin, and others. Among the inhibitors are BMP2, BMP4, activators of protein kinase $\mathrm{C}$ and others (Fig. 2B).

While it is not surprising to have an equilibrium of activators and inhibitors during periodic patterning (reviewed in Held, '92; Meinhardt, '82), as is found in lung morphogenesis (Hogan, '99), it was surprising in this case, to find that both activators and inhibitors are expressed within the feather primordia, not one in the primordial region and the other in the inter-primordial region. This finding renders models based on predetermination as unlikely, and suggests some fundamentally different mechanism underlies the organization of skin appendages. The mechanism that can explain this type of expression pattern is the reactiondiffusion model (Fig. 2B; Turing, '52; Jung et al., '98;).

\section{A novel reconstitution assay}

The problem with some of the previous models may not be that they are wrong, but that they used experimental systems that did not represent the most initial homogenous state.

Disparate position information (Wolpert, '71) and differential adhesion (Steinberg, '75) are likely to play a role in development, but these apply only after molecules expressed in the de novo mode (see above) are established. To identify earlier processes events that are in operation during the initial restrictive expression phase need to be examined. Therefore, an assay that starts from a homogeneous state is needed. After trying several protocols, a unique assay in which the epithelium is separated from the mesenchyme was established. The intact epithelium is then recombined with dissociated mesenchymal cells (Fig. 2C; Jiang et al., '99). Using this assay, several surprising findings were revealed. 1) After dissociation into single cells, these cells can still form a periodic pattern, suggesting that the patterning is a self-organizing process, and the information required for this organization is stored in floating single mesenchymal cells. Neither pre-existing order nor cues from the extracellular environment are required. 2) All the feather primordia appeared simultaneously at 24 hours, rather than sequentially. This suggests that the sequential appearance observed in vivo is not a prerequisite for the periodic pattern formation of feather buds. It is an additional global event superimposed on top of the local periodic patterning process. 3) A test was needed to determine whether the feather primordial mesenchyme has memory or is different to start with. Primordial mesenchymal cells labeled with DiI, a lipophilic dye that is passed on to 
daughter cells, were used in the reconstitution procedure. After reconstitution, the DiI positive cells were randomly distributed inside and outside the primordia, suggesting that all competent mesenchymal cells are reset to an equivalent state and have the same probability of becoming either part of the primordia or part of the inter-primordial regions. 4) To test whether the epidermal placode may serve as the organizing center for primordia, placodal cells were labeled with DiI and used in a reconstitution experiment. If the placode was the organizer, all the newly formed primordia would be under the original DiI labeled placode. The results showed that new primordia form without regard to the original placode positions. Again this suggests that the cells have an innate ability to form patterns and the location of individual cells is not predetermined.

In a reaction-diffusion mechanism (Turing, '52; Nagorcka and Mooney, '85; Moore et al., '98; Jung and Chuong, '98), the activators stimulate their own synthesis, and surprisingly that of inhibitors which limit their synthesis, leading to lateral inhibition. Subsequent work showed that FGF4 and SHH induced BMP-2, -4, which subsequently suppressed SHH and FGF4 synthesis (Jung et. al., '98; Jiang et al., '99). Furthermore, follistatin, an antagonist of BMP, was also induced within the feather primordia (Patel et al., '99). Using bead implantation, the fact that activators can induce both activators and inhibitors, and inhibitors can suppress the secretion of activators was confirmed (Jung et al., '98).

To test the effects of the activators and inhibitors, the cellular events during the restrictive expression phase was examined. The initial event may be driven by cell adhesion when the mildly adhesive cells reach a threshold cell density. The homogenous mesenchymal cells then form many small cellular aggregates (10-25 cells in size). These microaggregates condense into bigger aggregates, but the adhesions are reversible at this stage and the bigger aggregates are unstable. As condensed aggregates get larger, the above activator/inhibitor mechanism is initiated and the formation of the dermal condensations is consolidated. At this stage, these condensations send the " 1 st dermal message" to the epidermis to form the placode (Hardy, '68; Chuong et al., '96).

\section{Regulation of the number and size of feather primordia}

While periodic patterning processes can produce individual primordial elements, how are variations in the size, number, and spacing of feather primordia regulated? The feather reconstitution assay offered an opportunity to test this, by recombining a fixed sized epithelium with different numbers of mesenchymal cells. When increasing numbers of mesenchymal cells were used, two possibilities were expected: 1) increasing sizes of primordia, but with the same number; or 2) increasing numbers of primordia, but with a constant size. The results showed that for mesenchymal cells derived from the same region, the feather primordia were always of the same size (Jiang et al., '99; Fig. 2D). The way the number of primordia increased also provided insight to feather patterning. At very low numbers of mesenchymal cells, no primordia form. As mesenchymal cells gradually increase in number, feather buds start to form, each with a lateral inhibitory zone. Primordia first appear at random positions, not as aborted rows of a hexagonal lattice. As more mesenchymal cells are used, the number of primordia increases until it reaches a maximal 
packing density, and feathers appear to be arranged in a hexagonal pattern (Fig. 2D). However, this hexagonal pattern is the result of molecular and cellular equilibrium, not a consequence of preset molecular codes.

The size of the feather primordia can indeed differ from one feather tract to another, such as those seen in the wing tract and spinal tract. How does this happen? The reaction-diffusion model predicts that the ratio of activator and inhibitor will determine the size (the diameter) of the element (feather primordia). In this case, the ratio depends on the concentration of activator or inhibitor ligands, the number of their receptors, and the number of downstream signaling molecules. If this model was correct, the size of primordia could be modulated simply by changing the ratios of these parameters. Indeed, when the number of BMP receptors is increased, feather primordia become smaller. When Noggin, a BMP inhibitor, is increased in the system, feather primordia become bigger (Fig. 2E; Jiang et. al., '99).

Thus, periodic patterning within a feather tract field is a self-organizing process leading to the formation of individual feather primordia with characteristic sizes and numbers, depending on the properties of the cells. It is a process where the competent mesenchymal cells compete for the available and limited area of the competent epidermis. The final stable pattern results from competition and equilibrium of cell interactions.

\section{FURTHER REGIONALIZATION WITHIN A FEATHER PRIMORDIUM CONFERS FEATHER BUDS WITH AN ANTERIO-POSTERIOR AXIS, WHICH SUBSEQUENTLY LEADS TO THE FORMATION OF THE PROXIMO-DISTAL}

\section{AXIS}

In view of the importance of flight, the orientation of feathers is of critical importance. The site at which the rachis is inserted is defined as the anterior end of the feather bud. The pigeon shown in Figure 2A has contour feathers around the neck region in reverse orientation. When feather primordia initially form, the mesenchymal cells are homogenous. This can be demonstrated by epithelial - mesenchymal recombination experiments. If the epithelium is rotated 90 degrees prior to recombination, the feather orientation is set to the direction dictated by the epithelium (Novel, '73; Chuong et al., '96). The next step of morphogenesis occurs within the primordia where proliferation generates new cell mass for subsequent molding and morphogenesis. The primordia soon develop an anterior - posterior axis with more cell proliferation in the posterior end of feather buds (Desbiens et al., '92; Chen et al., '97). This is also evident in the expression pattern of molecules known to be important in the morphogenesis of a number of organ systems (Fig. 3B). Wnt-7a and $\beta$ catenin are expressed in a solid circular pattern. Sonic hedgehog, BMP-2, Delta-1, R-fringe and Eph-A4 are expressed with the central dot pattern. R-fringe initiates with a ring pattern. However, the patterns also change dynamically. For instance, Wnt- $7 \mathrm{a}$ and $\beta$-catenin soon move from a solid circle of expression to a ring pattern. Later as the feather buds begin to develop asymmetries, many genes become asymmetrically expressed. For example, tenascin-C and BMP-2 are expressed in the anterior region of the feather buds. Wnt-7a, $\beta$ catenin, L-fringe and Eph-A4 are expressed in the posterior region of the feather buds. Still others, like Notch-1, are expressed as a central stripe which later takes on some posterior 
expression within the feather buds. At this time, Delta- 1 is expressed in a complementary fashion within the boundaries of the Notch-1 expression domain. L-fringe is expressed toward the lateral edge of the feather bud. Hence, as feather buds develop, the feather bud is divided into a number of sub-domains with different molecular expression profiles (Fig. 3B,C).

What is the functional significance of these domains along the anterior - posterior axis and how they are regulated? Orientation signaling originates from the epithelia at E6, and more cells were found in the posterior bud domain at E7 (Desbiens et al., '92, Chen et al., '97; Fig. 3B). When the feathers elongate at E8, the posterior feather buds contribute more cells to the future feather bud (Chuong et al., '98). What molecules may account for this difference? Using in situ hybridization to show the distribution of RNA within cells, enhanced expression of Delta-1, Serrate-1 and some FGF receptors were found in the posterior feather bud (Noji et al., '93; Chen et al., '97). However Delta-1 was in the mesenchyme. What molecule could be in the epithelium to direct these differences? Wnt-7a was expressed in the posterior bud epithelium (Chuong et al., '96). Over-expression of Wnt-7a caused feather buds to stop elongating and to become plateau-shaped appendages (Fig. 3D; Widelitz et al., '99). Although cell proliferation was increased in these Wnt 7a over-expressing buds, the whole buds do not elongate and show characteristics of posterior feather buds without anterior - posterior and proximo - distal axes.

Previously, it was shown that activators for protein kinase A, such as cyclic-AMP, also arrested feather bud growth. But these arrested buds are round and small (Noveen et al., '95). They are deficient in cell proliferation, and express characteristics of anterior feather buds, such as the loss of sonic hedgehog expression (Noveen et al., '95, '96). Thus, the coexistence and interaction of juxtaposed anterior and posterior bud domains appear to be important for the generation of a new growth zone at their interface that will drive the growth of the proximo-distal axis of feather buds (Fig. 3D). This juxtaposition of domains is reminiscent of the situation in Drosophila and chicken limb development (LeCuit and Cohen, '97; Kengaku et al., '98).

\section{Localized bud growth zone and follicle collar zone}

The continued elongation of feather buds depends on the generation of a cell proliferation center in the feather buds. First these localized growth zones are found at the distal end of the feather bud, in a region enriched with SHH, NCAM, etc. The proximo - distal axis starts to elongate when focal cell proliferation adds cells to the distal tip of feather buds. However, when elongated feather buds start to invaginate into the dermis to form the follicles, the localized growth zone starts to descend to the flank region of feather buds and eventually comes down to the collar epithelia, adjacent to the dermal papilla (Chodankar et al., 2003; Fig 3E).

This growth mode of the feather is different from limb appendage development. In the limb, the growth zone, composed of the apical ectodermal ridge and the progress zone, remains in the distal end during development. Later, this growth zone disappears, losing its ability for further elongation or regeneration. In contrast, skin appendages, including feathers and hairs, form follicles and keep the growth zone cells and stem cells in the protected follicle. The 
continued interaction between the dermal papilla and collar epithelia produce sustained cell proliferation that drives proximo - distal elongation of the feather bud. By keeping stem cells protected in the follicle, they also allow future feather/hair cycling and regeneration. Scales have more diffuse growth zones and do not elongate. The lack of a localized growth zone may be one of the reasons that avian scales and most reptile scales can not grow long, except a few examples of reptile frills, such as those found on the back of an iguana's neck.

\section{FEATHER BRANCHING AT THREE LEVELS, THE RACHIS, BARBS AND BARBULES OFFER MORE OPPORTUNITIES FOR DIVERSITY. MODULATING THEIR SIZE, ANGLE AND SYMMETRY GENERATES COMPLEX FEATHER FORMS}

Contour feathers are made of a major branch named the rachis, secondary branches named barbs, and tertiary branches named barbules (Lucas and Stettenheim, '72; Gill, '94). To be more specific, a barb is made of a ramus and many barbules (Fig. 4 A,B). In the ramogenic zone, feather branching starts to be formed by the transformation of the cylindrical collar into periodically arranged barb ridges. The basal layer faces the pulp in the center. The basal layer cells are initially equivalent, but then become specified to be the marginal plate epithelia or barb ridges.

The downy feathers are radially symmetric with all the barbs inserted directly into the collar epithelium. Therefore the rachis is missing or is very short with all barbs inserted into it (Fig. 4E, panel a). Most adult contour feathers are bilaterally symmetric (Fig. 4E, panel b, c). In these feathers, barb ridges fuse at the anterior end, forming the rachidial ridge, which elongates distally. It leads to the formation of a long rachis with the continued insertion of barbs. If barbs form with the same length and angle, they form a bilaterally symmetric vane, like some flight feathers (Fig. 4E, panel e). The basis of left-right asymmetry remains to be worked out. It is reasonable to suggest that the key issues are the determination of the location of the rachis, the new barb forming zone within the collar (Fig. 4B), as well as the growth rate and angle (toward the rachis) of barb ridges. Theoretical models on how these processes may occur were proposed by Prum ('99) and Prum and Williamson (2001). Also see Prum and Dyck, this issue.

\section{Barbules form within the barb ridge}

The two columns of barb plate epithelia will become distal (the side that is closer to the rachis) and proximal barbules respectively (Fig. 4B). In a cross section, the rows of barb plate epithelia will become components of different barbules inserted at different levels of the ramus, with the more peripheral rows belonging to the barbules that insert at the lower level of the ramus. Here, the periodic patterning of barbules has come down to the single cell level, and the spacing between barbules was generated from the inter-cellular spaces. The length of the single cell wide individual barbule depends on the "height" of the barb ridge, which is determined by the rate of differentiation (starting from the periphery; O'Guin and Sawyer, '82) and the rate of growth in the ramogenic zone. When the proximal and distal barbules are of the same shape, they do not hook up with each other and thus form 
plumulaceous feathers that are fluffy (Fig. 4E, panel a, d). In a more evolved form, the two rows of barb plate epithelia become asymmetric. Distal barbules develop hooklets that will hook onto the proximal barbules of the barbs distal to it. Thus, they form pennaceous feathers that are tightly interlocked (Fig. 4E, panel b, c, e).

From these descriptions, one can appreciate that feather forms are determined by the combination of the number, size and shape of the rachis, barbs and barbules, with different levels of symmetry and asymmetry. For example, the width of a feather is determined by the length of barbs and the angle at which the barbs insert into the rachis (See Prum and Williamson, 2001 for theoretical model and possibilities). The length of a feather is determined by the length of the rachis, or the length of the anagen phase of the feather cycle. The texture of the vane is influenced by the spacing of barbs and characteristics of barbules (plumulaceous versus pennaceous, see above). What are the molecular pathways that determine each of these parameters? If some of these can be understand, it may lead to a better understanding of the evolution of feather forms and how the feather diversity seen today was made. To this end, RCAS retroviral vector mediated gene transduction was applied to regenerating feathers. The efficiency of gene mis-expression is high (Fig. 4C; $\mathrm{Yu}$ et al., 2002), and the application of this technology has just begun.

Here one example utilizing this approach to perturb BMP and SHH expression, which alters feather branching, is shown (Fig. 4D; Yu et al., 2002). BMP4 is expressed in the dermal papilla and proximal pulp. Its expression levels are gradually reduced toward the distal pulp. Noggin, a BMP antagonist, is expressed in the pulp at the level of the ramogenic zone, where branching starts. Shh is expressed in the marginal plate epithelia (Ting-Berreth and Chuong, '96a). When BMP4 is mis-expressed, rachis formation is enhanced and barbs fuse. When noggin is mis-expressed (Fig. 4C,D), the rachis is split and increased barb branching ensues. Suppression of Shh can inhibit the apoptotic cell death in marginal plate epithelia, leading to a webby membrane remnant between barbs. Thus, BMP and SHH pathways are involved in regulating the formation and balance among the rachis and barbs. More of these approaches should help to reveal the molecular mechanisms of feather forms.

\section{PLUMAGE PHENOTYPES ARE FURTHER BUILT UPON GRADED CHANGES OF ADJACENT FEATHERS WITHIN THE SAME TRACTS AND GLOBAL DIFFERENCES AMONG DIFFERENT FEATHER TRACTS}

Another level of morphological variation is the gradual modulation of the above parameters within a single feather or across a feather tract. For each of the parameters, the changes can be graded in different portions of the feather across a feather tract. For example, from the base, a feather can have a plumulaceous region that covers, e.g., about $10 \%$ of the feather that increases in a graded fashion across the tract to become approximately $90 \%$ of the feather. Along the remige (flight feather) tract, the lateral vanes also decrease sharply in width toward the lateral side (or distal limb). According to biomechanical analysis, this shape modification is essential for good performance in flight aerodynamics (Feduccia, 2001). The ability to vary the plumulaceous to pennaceous ratio adds more complexity to the form and function of avian plumages. 
Among different tracts, differences in size (heterochrony) and morphology (regional specificity) can occur. By adjusting the relative size of feathers in different tracts, a bird will assume particular body contours, and different parts of the integument can serve distinct functions. For example, when a chicken is just hatched, trunk feather buds are longer than wing remiges because maintaining warmth is the top priority. Flight feathers soon catch up in development to enable flight. Similarly the differential feather growth of budgies is mostly clear (Fig. 5). The mechanism of size regulation can be based on differences in growth rate or duration of growth period.

Sexual dimorphism adds yet another level of complexity to feather diversity. These secondary sexual characteristics are so important in mate selection, that some birds have elaborate plumage, sacrificing functionality for ornamental display and privilege to mate. Sexual hormones can influence the size, shape or color of feathers. For example, the spectacular peacock retrice feathers only exist in mature males (Fig. 4E, panel d). The ability and plasticity of skin appendages to generate different morphology through changes in hormones make it a sophisticated communication media and contribute to species formation (Grant and Grant, '97).

\section{SUMMARY}

Restructuring the originally homogeneous integument initiates the making of a feather.

Continuous building of multiple levels of symmetry and asymmetry leads to these complex epithelial appendages. For the described basic morphogenetic process of a feather, modulating the size, angle, and asymmetry of the three-leveled branches (rachis, barbs, and barbules) can generate diverse feather forms. With recent advances, developmental biology has matured and integrated with evolutionary biology to form the new field of Evo-Devo (Davidson, 2001). Among the different aspects of Evo-Devo research, one of the major goals is to understand their molecular basis, and how modulation of molecular pathways can alter developmental mechanisms, leading to distinct morphological phenotypes (Wagner, 2000) that may have major consequences in evolution. With the ability to modulate molecular pathways in chicken integument development, it should be possible to analyze the molecular basis of these morphogenesis parameters experimentally. The distinct patterns and forms of feathers provide an excellent biological model that can be appreciated by scientists of different disciplines to learn how Nature uses different strategies to build complex structures from simple forms.

\section{ACKNOWLEDGMENT}

We are thankful for support from the NIH (RW CA83716; CMC AR42177, AR47364) and NSF (IBN9808874). We thank Ms Maji Ramos for help in preparing the manuscript. We also thank Jimmy Evans and Steven Widelitz for the feather in Fig. 4E panel $d$. Figure 3A is from Lucas and Stettenheim, '72.

\section{LITERATURE CITED}

Bartels T, Meyer W, Neurand K. Skin and plumage changes in domestic birds. II. Plumage changes Tierarztl Prax. 1992; 20:275-281.

Brantjes H, Barker N, van Es J, Clevers H. TCF: Lady Justice casting the final verdict on the outcome of Wnt signalling. Biol Chem. 2002; 383:255-261. [PubMed: 11934263] 
Chen CWJ, Jung HS, Jiang TX, Chuong CM. Asymmetric expression of Notch, Serrate and Delta is associated with the anterior posterior axis of feather buds. Dev Biol. 1997; 188:181-187. [PubMed: 9245521]

Chen CW, Chuong CM. Avian integument provides multiple possibilities to analyse different phases of skin appendage morphogenesis. J Investig Dermato. Symp Proc. 1999; 4:333-337.

Chen CWJ, Chuong CM. Dynamic expression of lunatic fringe during feather morphogenesis: a switch from medial-lateral to anterior-posterior asymmetry. Mech Dev. 2000; 91:351-354. [PubMed: 10704863]

Chodankar R, Chang C-H, Yue Z, Jiang T-X, Suksaweang S, Burrus LW, Chuong C-M, Widelitz RB. Shift of localized growth zones contributes to skin appendage morphogenesis: Role of the Wnt/âcatenin pathway. J Investig Dermatol. 2003; 120:20-26. [PubMed: 12535194]

Chuong CM. The making of a feather: homeoproteins, retinoids and adhesion molecules. Bioessays. 1993; 15:513-521. [PubMed: 7907866]

Chuong CM, Ting-Berreth S, Widelitz RB, Jiang TX. Early events during the regeneration of skin appendages: order of molecular reappearance following epithelial-mesenchymal recombination with rotation. J Invest Dermatol. 1996; 107:639-646. [PubMed: 8823374]

Chuong, CM. Morphogenesis of epithelial appendages: Variations on top of a common theme and implications in regeneration. In: Chuong, CM., editor. Molecular basis of epithelial appendage morphogenesis. R.G. Landes; Georgetown, TX: 1998. p. 3-13.

Chuong CM, Jung HS, Noden D, Widelitz RB. Lineage and pluripotentiality of epithelial precursor cells in developing chicken skin. Biochem Cell Biol. 1998; 76:1069-1077. [PubMed: 10392717]

Chuong CM, Chodankar R, Widelitz RB, Jiang TX. Evo-Devo of feathers and scales: building complex epithelial appendages. Curr Opin Genet Dev. 2000; 10:449-456. [PubMed: 11023302]

Chuong CM, Hou L, Chen PJ, Wu P, Patel N, Chen Y. Dinosaur's feather and chicken's tooth? Tissue engineering of the integument. Eur J Dermatol. 2001; 11:286-292. [PubMed: 11399531]

Crowe R, Henrique D, Ish-Horowicz D, Niswander L. A new role for Notch and Delta in cell fate decisions: patterning the feather array. Development. 1998; 125:767-775. [PubMed: 9435296]

Davidson, E. Genomic Regulatory Systems: Development and Evolution. Academic Press; New York: 2001.

Desbiens X, Turque N, Vandenbunder B. Hydrocortisone perturbs the cell proliferation pattern during feather morphogenesis: evidence for disturbance of cephalocaudal orientation. Int J Dev Biol. 1992; 36:373-380. [PubMed: 1445781]

Feduccia A. Digit homology of birds and dinosaurs: accommodating the cladogram. Trends Ecol Evol. 2001; 16:285-286. [PubMed: 11369105]

Gat U, Dasgupta R, Degenstein L, Fuchs E. De novo hair follicle morphogenesis and hair tumors in mice expressing a truncated $\beta$-catenin in skin. Cell. 1998; 95:605-614. [PubMed: 9845363]

Gill, FB. Ornithology. 2nd edition. Freeman; New York: 1994.

Grant PR, Grant BR. Genetics and the origin of bird species. Proc. Natl. Acad. Sci. USA. 1997; 94:7768-7775. [PubMed: 9223262]

Hardy MH. Glandular metaplasia of hair follicles and other responses to vitamin A excess in cultures of rodent skin. J. Embryol Exp Morphol. 1968; 19:157-180. [PubMed: 4872188]

Held, LI. Models for Embryonic Periodicity. Karger; New York: 1992.

Hogan BL. Morphogenesis Cell. 1999; 96:225-233.

Huelsken J, Vogel R, Erdmann B, Cotsarelis G, Birchmeier W. $\beta$-Catenin controls hair follicle morphogenesis and stem cell differentiation in the skin. Cell. 2001; 105:533-545. [PubMed: 11371349]

Jiang TX, Chuong CM. Mechanism of skin morphogenesis. I. Analyses with antibodies to adhesion molecules tenascin, N-CAM, and integrin. Dev Biol. 1992; 150:82-98.

Jiang TX, Jung HS, Widelitz RB, Chuong CM. Self organization is the initial event in periodic feather patterning: Roles of signaling molecules and adhesion molecules. Development. 1999; 126:49975009. [PubMed: 10529418] 
Jung, HS.; Chuong, CM. Periodic pattern formation of the feathers. In: Chuong, CM., editor. Molecular basis of epithelial appendage morphogenesis. R.G. Landes; Georgetown, TX: 1998. p. 359-369.

Jung HS, Francis-West PH, Widelitz RB, Jiang TX, Ting-Berreth S, Tickle C, Wolpert L, Chuong CM. Local inhibitory action of BMPs and their relationships with activators in feather formation: implications for periodic patterning. Dev Biol. 1998; 196:11-23. [PubMed: 9527877]

Kengaku M, Capdevila J, Rodriguez-Esteban C, De la Pena J, Johnson RL, Izpisua-Belmonte JC, Tabin CJ. Distinct WNT pathways regulating AER formation and dorsaoventral polarity in the chick limb bud. Science. 1998; 280:1274-1277. [PubMed: 9596583]

Lecuit T, Cohen SM. Proximal-distal axis formation in the Drosophila leg. Nature. 1997; 388:139145. [PubMed: 9217152]

Lucas, AM.; Stettenheim, PR. Agriculture Handbook 362: Agricultural Research Services. US Department of Agriculture; Washington DC.: 1972. Avian Anatomy: Integument.

Mayerson PL, Fallon JF. The spatial pattern and temporal sequence in which feather germs arise in the white Leghorn chick embryo. Dev Biol. 1985; 109:259-267. [PubMed: 3996749]

Meinhardt, H. Models of biological pattern formation. Academic Press; New York, NY: 1982.

Moore GP, Jackson N, Isaacs K, Brown G. Pattern and morphogenesis in skin. J Theor Biol. 1998; 191:87-94. [PubMed: 9593659]

Morgan BA, Fekete DM. Manipulating gene expression with replication-competent retroviruses. Methods Cell Biol. 1996; 51:185-218. [PubMed: 8722477]

Murray JD, Oster GF, Harris AK. A mechanical model for mesenchymal morphogenesis. J Math Biol. 1983; 17:125-129. [PubMed: 6875405]

Nagorcka BN, Mooney JR. The role of a reaction-diffusion system in the initiation of primary hair follicles. Theor Biol. 1985; 114:243-272.

Noji S, Koywam E, Myokai F, Nohno T, Ohuchi H, Nishikawa K, Taniguchi S. Differential expression of three chick FGF receptor genes, FGFR1, FGFR2 and FGFR3, in limb and feather development. Prog Clin Biol Res. 1993; 383B:645-654. [PubMed: 8115380]

Noramly S, Morgan BA. BMPs mediate lateral inhibition at successive stages in feather tract development. Development. 1998; 125:3775-3787. [PubMed: 9729486]

Noramly S, Freeman A, Morgan BA. $\beta$-catenin signaling can initiate feather bud development. Development. 1999; 126:3509-3521. [PubMed: 10409498]

Noveen A, Jiang TX, Chuong CM. Protein kinase A and protein kinase C modulators have reciprocal effects on mesenchymal condensation during skin appendage morphogenesis. Dev Biol. 1995; 171:677-693. [PubMed: 7556946]

Noveen A, Jiang TX, Chuong CM. cAMP, an activator of protein kinase A, suppresses the expression of sonic hedgehog. Biochem Biophys Res Commun. 1996; 219:180-185. [PubMed: 8619804]

Novel G. Feather pattern stability and reorganization in cultured skin. J Embryol. Exp Morphol. 1973; 30:605-633. [PubMed: 4772388]

O'Guin WM, Sawyer RH. Avian scale development. VII. Relationships between morphogenetic and biosynthetic differentiation. Dev Biol. 1982; 89:485-492. [PubMed: 6173277]

Olivera-Martinez I, Thelu J, Teillet MA, Dhouailly D. Dorsal dermis development depends on a signal from the dorsal neural tube, which can be substituted by Wnt-1. Mech Dev. 2001; 100:233-244. [PubMed: 11165480]

Olivera-Martinez I, Missier S, Fraboulet S, Thelu J, Dhouailly D. Differential regulation of the chick dorsal thoracic dermal progenitors from the medial dermomyotome. Development. 2002; 129:4763-4772. [PubMed: 12361968]

Oster GF, Murray JD, Harris AK. Mechanical aspects of mesenchymal morphogenesis. J Embryol Exp Morphol. 1983; 78:83-125. [PubMed: 6663234]

Patel K, Makarenkova H, Jung HS. The role of long range, local and direct signalling molecules during chick feather bud development involving the BMP's, follistatin and the Eph receptor tyrosine kinase Eph-A4. Mech Dev. 1999; 86:51-62. [PubMed: 10446265]

Prum RO. Development and evolutionary origin of feathers. J Exp Zool. 1999; 285:291-306. [PubMed: 10578107] 
Prum RO, Brush AH. The evolutionary origin and diversification of feathers. Q Rev Biol. 2002; 77:261-295. [PubMed: 12365352]

Prum RO, Willaimson S. Theory of the growth and evolution of feather shape. J Exp Zool. 2001; 291:30-57. [PubMed: 11335915]

Prum RO, Williamson S. Reaction-diffusion models of within-feather pigmentation patterning. Proc R Soc Lond B Biol Sci. 2002; 269:781-792.

Sengel, P. Morphogenesis of skin. Cambridge University Press; Cambridge: 1976.

Sengel P. Feather pattern development. CIBA Found Symp. 1978; 28:51-70.

Song H, Wang Y, Goetinck PF. Fibroblast growth factor 2 can replace ectodermal signaling for feather development. Proc Natl Acad Sci USA. 1996; 93:10246-10249. [PubMed: 8816784]

Steinberg MS. Adhesion-guided multicellular assembly: a commentary upon the postulates, real and imagined, of the differential adhesion hypothesis, with special attention to computer simulations of cell sorting. J Theor Biol. 1975; 55:431-443. [PubMed: 1207170]

Ting-Berreth SA, Chuong CM. Sonic Hedgehog in feather morphogenesis: induction of mesenchymal condensation and association with cell death. Dev Dyn. 1996a; 207:157-170. [PubMed: 8906419]

Ting-Berreth SA, Chuong CM. Local delivery of TGF $\beta 2$ can substitute for placode epithelium to induce mesenchymal condensation during skin appendage morpho-genesis. Dev Biol. 1996b; 179:347-359. [PubMed: 8903351]

Turing AM. The chemical basis of morphogenesis. Phil Trans R Soc B. 1952; 237:37-72.

Viallet JP, Prin F, Olivera-Martinez I, Hirsinger E, Pourquie O, Dhouailly D. Chick Delta-1 gene expression and the formation of the feather primordia. Mech Dev. 1998; 72:159-168. [PubMed: 9533960]

Wagner GP. What is the promise of developmental evolution? Part I: why is developmental biology necessary to explain evolutionary innovations? J Exp Zool. 2000; 288:95-98. [PubMed: 10931493]

Widelitz RB, Jiang TX, Noveen A, Chen CW, Chuong CM. FGF induces new feather buds from developing avian skin. J Invest Dermatol. 1996; 107:797-803. [PubMed: 8941663]

Widelitz RB, Jiang TX, Cheng CW, Stott NS, Chuong CM. Wnt-7a in feather morphogenesis: involvement of anterior-posterior asymmetry and proximal-distal elongation demonstrated with an in vitro reconstitution model. Development. 1999; 126:2577-2587. [PubMed: 10331970]

Widelitz RB, Jiang TX, Lu J, Chuong CM. $\beta$-catenin in epithelial morphogenesis: Conversion of part of avian foot scales into feather buds with a mutated $\beta$-catenin. Dev Biol. 2000; 219:98-114. [PubMed: 10677258]

Wolpert L. Positional information and pattern formation. Curr Top Dev Biol. 1971; 6:183-224. [PubMed: 4950136]

Yu M, Wu P, Widelitz RB, Chuong CM. The morphogenesis of feathers. Nature. 2002; 420:308-312. [PubMed: 12442169]

Zhu AJ, Watt FM. $\beta$-catenin signaling modulates proliferative potential of human epidermal keratinocytes independently of intercellular adhesion. Development. 1999; 126:2285-2298. [PubMed: 10207152] 

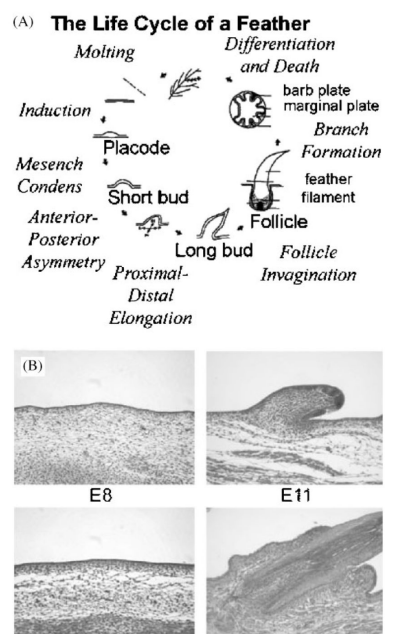

E8

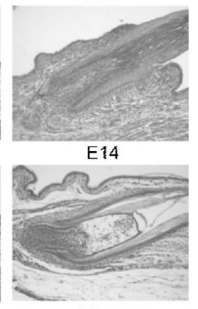

E9

E20

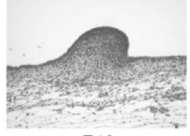

E10

Fig. 1.

The process of feather formation involves temporal and spatial regulation of cellular processes, including localized cell proliferation, migration, adhesion, death and differentiation. A. The life cycle of a feather: the stages and major morphogenetic processes in feather development are listed. B. Haemotoxylin and eosin stained tissue sections of developing feathers from dorsal skin: at E7, it is flat. At E 8, dense dermis starts to form. At E9, feather primordia form. At E10, feather buds form. At E11, buds have elongated. At E14, buds invaginate to form follicles. At E20, a new feather is forming. 


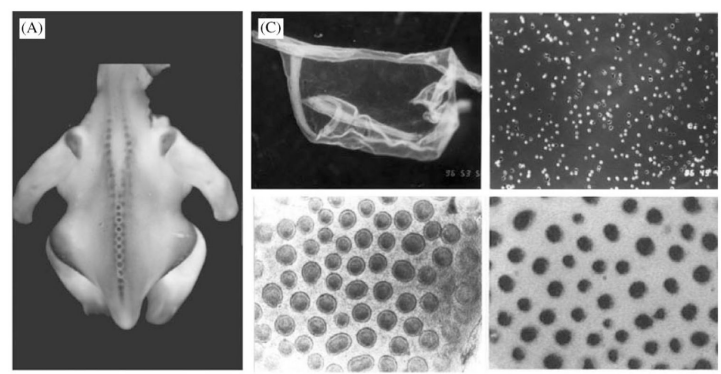

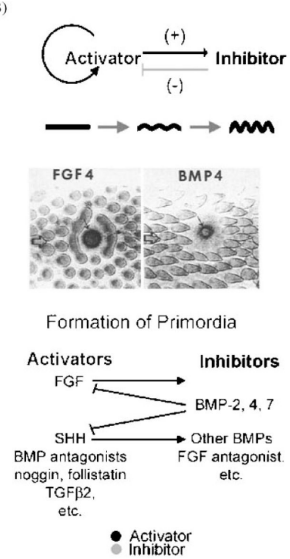

(D) REGULATION OF PRIMORDIUM NUMBERS

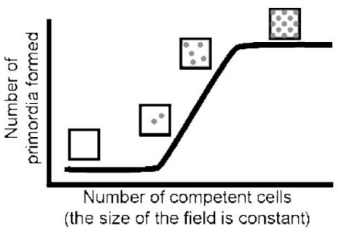

(E) REGULATION OF PRIMORDIUM SIZE

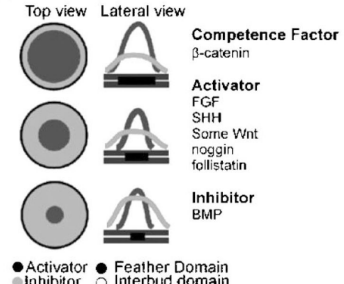

Fig. 2.

Periodic patterning of feather primordia within the feather tract field. It is a self-organizing process, based on the interplay of molecules with positive or negative roles on feather primordia formation. It results in individual feather buds of certain size and numbers. A. $\beta$ catenin marks the initial appearance of feather primordia: during development, the $\beta$-catenin transcript is first expressed in the whole tract field, then becomes restricted to individual feather primordia with a lateral inhibitory zone (Widelitz et al., 2000). B. Feather periodic patterning involving reaction-diffusion and competitive equilibrium: through experimentation, some molecules are found to enhance feather formation (activators), and some suppress feather formation (inhibitors). An exemplary activator (FGF 4) and inhibitor (BMP 4) are shown. Data show that both activators and inhibitors are located in the primordial region, not one in the primordia and one in the inter-primordia, respectively. The activators induce both activators and inhibitors, while the inhibitors suppress the activators. These results favor the involvement of a reaction-diffusion mechanism (Turing, '52; Nagorcka and Mooney, '85; Moore et al., '98; Jiang et al., '99). C. A novel reconstitution assay that allows the study of periodic pattern formation from a zero state: Upper panels. Embryonic day 6 chicken skin was dissected, and epidermis (upper left panel) and mesenchyme were separated. Mesenchyme was dissociated into single cells (upper right panel). Lower panels. Cells are recombined with epithelium and cultured. In 24 hours, they self-organize into many feather buds simultaneously (lower left panel, Jiang et al., '99). These buds start to express bud specific genes such as SHH (lower right panel, Ting-Berreth and Chuong, '96a). D. Regulation of the number of feather primordia: Using the reconstitution assay, the effect of using a fixed size of epidermis while increasing the number of competent mesenchymal cells was tested. Logically, either the number of buds or 
the size of the feather primordia could increase. Using skin from a certain region, it was found that the size of the feather primordia is a constant. At low cell density, buds did not form. At higher cell density, feather primordia started to appear randomly. The density of feather primordia gradually increased until they reached the highest packing density, which yields the hexagonal patterning (Jiang et al., '99). E. Regulation of the size of feather primordia: Competent cells are first distributed homogeneously in the field. These cells adhere randomly and this adhesion is reversible. When these small unstable aggregates surpass a threshold density, they become stable dermal condensations. The size of each dermal condensation is dependent on the ratio of activator molecules (noggin, FGF, Shh, etc) to inhibitor molecules (BMPs). A higher activator to inhibitor ratio allows the formation of larger sized feather buds while a higher inhibitor to activator ratio favors the formation of the interbud region (Jiang et al., '99). 


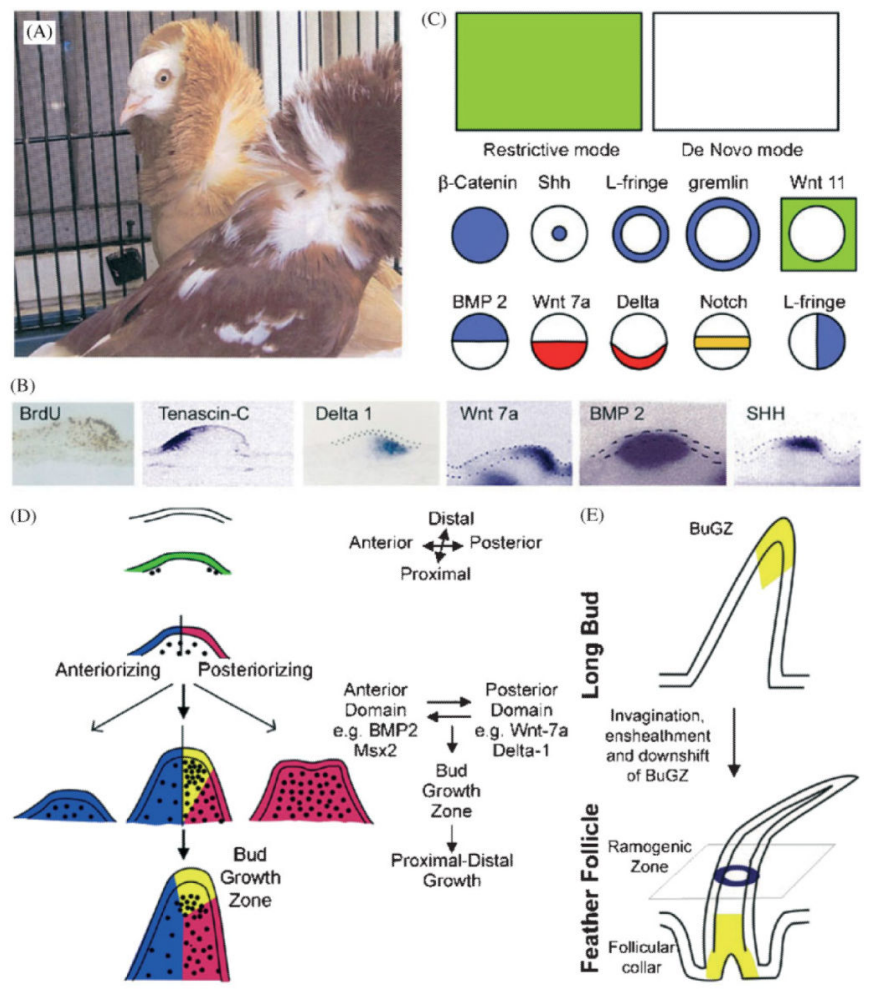

Fig. 3.

Further regionalization within feather buds: It involves setting up anterior - posterior asymmetric long feather buds and a proximal - distal axis. A. Orientation of the feather: when feather primordia first form, they have no orientation. Soon, they acquire anteriorposterior asymmetry from the epithelium (Novel, '73; Chuong et al., '96). The anterior end is the side of the future rachis. Feather orientation is essential to feather function in view of the need for flight. However, the orientation signal can go wrong as seen in these two genetic variants of the pigeon. Feathers in the scapular feather tract are inversely oriented. Individual feathers are otherwise normal. B. Molecular asymmetry of the feather buds: cell proliferation is enriched in the posterior buds. Tenascin- $\mathrm{C}$ is in the anterior mesenchyme (Jiang and Chuong, '92). Delta-1 is in the posterior bud mesenchyme (Chen et al., '97), Wnt $7 \mathrm{a}$ in the posterior epithelium (Chuong et al., '96), BMP 2 in the mesenchyme (Jung et al., '98) and SHH in the distal epithelium (Ting-Berreth and Chuong, '96a). Notice, while BMP 2 is a feather formation inhibitor, it is expressed in the feather primordia region. C. Schematic drawing of representative molecular expression modes: two general expression profiles for all molecules studied to date have been observed. In the restrictive mode, the genes are initially expressed throughout a feather tract field before the buds are formed, and later become restricted to specific regions of the buds or interbuds. In the de novo mode, they appear in specific regions of the buds or interbuds after the buds form. D. Coupling of anterior - posterior asymmetry and proximal - distal growth: experimental data suggest that the co-existence of anterior and posterior bud domains is critical for the proximal - distal elongation of buds (Noveen et al., '95a; Widelitz et al., '99). A bud growth zone (yellow) appears at the distal interface of the anterior (blue) and posterior (red) domains. At this stage, proliferation is highest within this bud growth zone. Some possible molecular 
relationships are listed. E. Growth zones in buds and follicle: at the time of invagination and ensheathment to form the feather follicle, the growth zone gradually shifts from the distal to the proximal end of the follicle, and becomes the collar (Chodankar et al., 2003). 


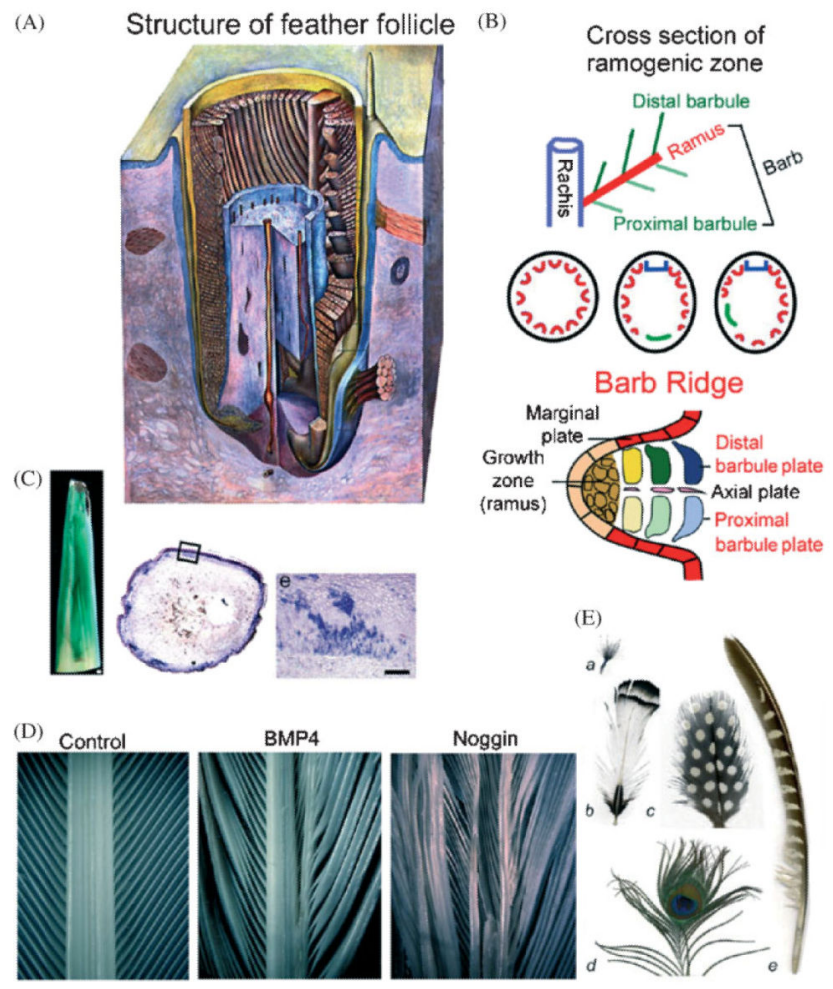

Fig. 4.

Branching morphogenesis of the feather: forming rachis, barbs and barbules. A new level of periodic patterning process within the cylindrical feather collar epithelium leads to the threeleveled hierarchal branches. Modulation of their size, angle and symmetry through molecular pathways can generate complex and diverse feather forms. A. A schematic drawing showing the inside of a forming feather filament (from Lucas and Stettenheim, '72): The ramogenic zone is the region in which the barb ridge starts to form. Its cross section is shown in panel B. B. Formation of rachis, barbs and barbule: from the cylinder shaped collar, feather barb ridges (Red) start to form in the ramogenic zone. This can occur in a radially symmetric fashion (middle left) and form downy feathers. Or, a rachis (blue) and a barb forming zone (green) are formed in a bilaterally symmetric (middle center) or asymmetric (middle right) fashion, leading to bilaterally symmetric or asymmetric vanes. Proximal and distal barbules (top, here as the proximal and distal barbule plates) can be the same or different, leading to plumulaceous or pennaceous vanes. C. RCAS mediated gene transduction of feathers: To generate feathers with mis-expressed genes, regenerating feathers are infected with RCAS chicken retrovirus. Ectopic expression of $\beta$ galactosidase and Noggin are shown. D. Alteration of feather branching by perturbation of the BMP pathway: Left, normal. Middle, Over-expression of BMP4 causes enlargement of rachis. Right, Over-expression of noggin causes splitting of the rachis. E. Examples of feathers showing different feather forms: $a$. Downy feather shows radially arranged barbs inserted on a short stalk. $b$. A contour feather with a bilaterally symmetric vane. $c$. A feather with a bilaterally symmetric vane. $d$. A bilaterally symmetric peacock retrice (tail feather). $e$. Highly asymmetric remige (flight feather) of a pheasant. Pigmentation patterns can be either symmetric stripes (b), spots, note the half spots surrounding the rachis (c), one "eye spot" 
(concentric rings) (d) or stripes on only one of the vanes (e) Model on how these patterns may form based on reaction diffusion was proposed by Prum and Williamson, 2002.

Plumulaceous barbs like those shown in $a$ and $d$ are due to symmetric barbules. Pennaceous barbs like those found in $b, c$ and $e$ are the results of asymmetric barbule formation. 


\section{Growth Rate of Different Feather Types}

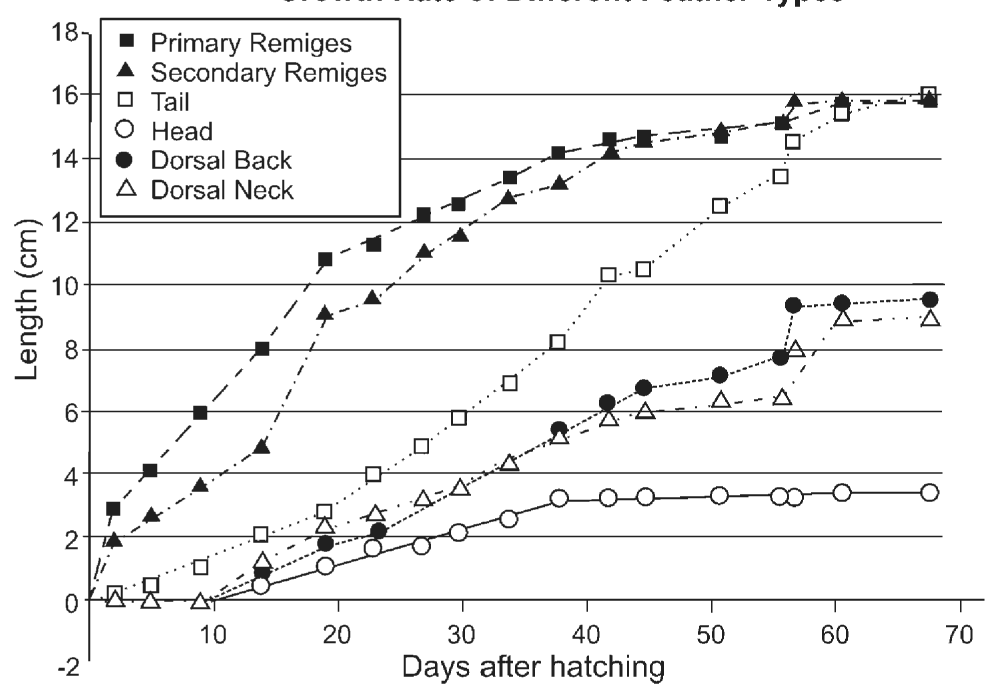

Fig. 5.

Different feather growth rate. The length of feathers from different skin regions from a budgie was measured. 